\title{
Prevalence of Metabolic Syndrome in Diabetic Patient
}

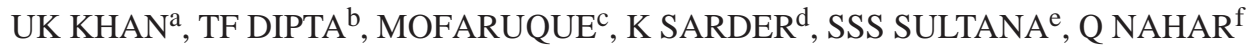

\begin{abstract}
Summary:
Background: Factors associated for the development of metabolic syndrome vary from region to region and race to race. Objectives: The present study aimed to assess the prevalence of metabolic syndrome and phenotype of newly diagnosed IGT and DM subjects. Methods: In this cross sectional study $100 \mathrm{DM}$ and 44 IGT subjects recruited from OPD BIRDEM hospital. BMI, Neck, and waist circumference, WHR and blood pressure were collected by skilled trainer using modern equipments. Serum glucose was measured by glucose-oxidase method and lipid profile was measured by enzymatic-colorimetric method. Results: Glycemic status was higher in diabetic subjects (12 $\pm 5 ; A B F$
\end{abstract}

\section{Introduction:}

Metabolic syndrome is a combination of medical disorders that increase the risk of developing cardiovascular diseases and diabetes ${ }^{1,2}$. Now it has become a major public health issue globally. It affects a great number of people and prevalence increases with age. Approximately $34 \%$ of adults meet the criteria for metabolic syndrome in USA. ${ }^{3}$

The bulk of problem is constantly increasing in developing countries like Bangladesh. According to

a. Umma K Khan, MSc, North South University

b. Tashmim F Dipta, FCPS, Assistant Prof \& Head, Dept of Transfusion Medicine

c. Md Omar Faruque, Senior Research Officer, Dept of Biochemistry and Cell Biology, BIRDEM

d. Dr Kawser Sarder, Associate Professor, Dept of Anesthesiology, BIRDEM

e. Syeda Saliha Saliheen Sultana, MSc, Assistant Prof., Dept of Food \& Nutrition, College of Home Economics

f. Quamrun Nahar, PhD, Senior Research Officer, Dept of Biochemistry and Cell Biology, BIRDEM

Address of Correspondence: Quamrun Nahar, Department of Biochemistry and Cell Biology, Bangladesh Institute of Research and Rehabilitation in Diabetes, Endocrine and Metabolic Disorders (BIRDEM), Room No 336A, 122, Kazi Nazrul Islam Avenue, Shahabg, Dhaka-1000 Bangladesh. e-mail: naharq@yahoo.com

Received: 28 June, 2011

Accepted: 13 March, 2012

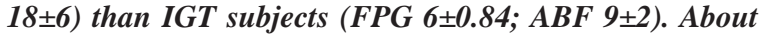
$39.6 \%$ subjects had metabolic syndrome according to the definition of EGIR and $\mathbf{2 1 . 9} \%$ were hypertensive in DM subjects. Neck circumference was positively correlated with BMI ( $r=0.4, p=0.02)$ and waist circumference ( $r=0.25 . p=0.003)$. Conclusions: Glycemic status affects at the BMI 24 and neck circumference $33 \mathrm{~cm}$ with age 40 years. About $39.6 \%$ MS present following EGIR but poor \% MS have found following ATP III and WHO criteria.

Key words: Metabolic syndrome, BMI, Neck circumference, ATP III

(J Bangladesh Coll Phys Surg 2012; 30: 85-90)

World Health Organization (WHO), Non Communicable Diseases (NCDs) are important cause of disease burden, morbidity and mortality in our country. Mortality, morbidity, and disability attributable to the major non-communicable diseases account for about $60 \%$ of all deaths and $47 \%$ of the global burden of disease; these rates are expected to rise in South Asia. Diabetes is one of the major NCDs and in Bangladesh, the prevalence of diabetes increases dramatically with a ratio in urban areas is double than in rural areas $(8 \%$ vs $4 \%$ ) and rises with affluence. The etiology of the metabolic syndrome has not yet been fully established. For most patients, the root causes of the non communicable diseases are thought to be poor nutrition, inadequate physical activity, subsequent increases in body weight, tobacco used, betel leaf chewing and smoking, excess alcohol consumption and low consumption of fruits and vegetables. Factors associated for the development of non-communicable diseases in one country is not applicable for another country. Factors associated for the development of non-communicable diseases vary from region to region and race to race. Risk factors should be targeted on individual, family and community, regional and national level.

Different organization had suggested different definition of metabolic syndrome. The more relevant definition for Asian is National Cholesterol Education Program 
(NCEP) Adult Treatment Panel III (ATP III). Metabolic syndrome define by ATPIII includes any of three or more of the following criteria:4, 5, 6 elevated waist circumference for men equal to or greater than 40 inches $(102 \mathrm{~cm})$; women equal to or greater than 35 inches $(88 \mathrm{~cm})$; elevated triglycerides: equal to or greater than $150 \mathrm{mg} / \mathrm{dL}$; reduced HDL ("good") cholesterol for men less than $40 \mathrm{mg} / \mathrm{dL}$; women less than $50 \mathrm{mg} / \mathrm{dL}$. Elevated blood pressure: equal to or greater than 130/ $85 \mathrm{~mm} \mathrm{Hg}$ or use of medication for hypertension, elevated fasting glucose: equal to or greater than 100 $\mathrm{mg} / \mathrm{dl}(5.6 \mathrm{mmol} / \mathrm{l})$ or use of medication for hyperglycemia ${ }^{6}$.

The World Health Organization criteria (1999) for the metabolic syndrome requires presence of diabetes mellitus, impaired glucose tolerance, impaired fasting glucose or insulin resistance, and two of the following: 4 blood pressure: e" 140/90 mmHg; dyslipidaemia: triglycerides (TG): e” $1.695 \mathrm{mmol} / \mathrm{L}$ and high-density lipoprotein cholesterol (HDL-C) d" 0.9 mmol/L (male), d” $1.0 \mathrm{mmol} / \mathrm{L}$ (female); central obesity: waist:hip ratio $>0.90$ (male); > 0.85 (female), and/or body mass index $>30 \mathrm{~kg} / \mathrm{m}^{2}$; microalbuminuria: urinary albumin excretion ratio e” $20 \mathrm{mg} / \mathrm{min}$ or albumin:creatinine ratio e” $30 \mathrm{mg} / \mathrm{g}$.

According to The European Group for the Study of Insulin Resistance (1999) requires insulin resistance defined as the top $25 \%$ of the fasting insulin values among non-diabetic individuals and two or more of the following: central obesity: waist circumference e” 94 cm (male), e” $80 \mathrm{~cm}$ (female); dyslipidaemia: TG e" $2.0 \mathrm{mmol} / \mathrm{l}$ and/or HDL-C $<1.0 \mathrm{mmol} / \mathrm{l}$ or treated for dyslipidaemia; hypertension: blood pressure e” 140/90 mmHg or antihypertensive medication; fasting plasma glucose e” $6.1 \mathrm{mmol} / \mathrm{L}(110 \mathrm{mg} / \mathrm{dl})^{7}$.

In comparison with the European subjects, the South Asian subjects had a higher prevalence of diabetes (19\% vs. $4 \%)^{8}$, higher blood pressures, higher fasting and post-glucose serum insulin concentrations, higher plasma triglyceride, and lower HDL-C concentrations. Mean waist-hip ratios were higher in the South Asian group than in the European group. Within each ethnic group, waist-hip ratio was correlated with glucose intolerance, insulin, blood pressure, and triglycerides. For the same waist-hip ratio, the Asian patients had a much higher risk of developing insulin resistance, hyperinsulinemia and diabetes.
The obesity epidemic is considered to be one of the main drivers of the rising prevalence of the metabolic syndrome. But the mechanisms underlying the association between abdominal obesity (particularly visceral obesity) and the metabolic syndrome are not fully understood. Insulin resistance is widely believed to be at the heart of the metabolic syndrome even though there is, as yet, little clinical evidence that a reduction in insulin resistance will prevent cardiovascular events in people with metabolic syndrome. The mechanistic link between insulin resistance and most of the components of the metabolic syndrome remains unclear. Non-diabetic patients with metabolic syndrome are at a very high risk for the development of diabetes. Risk is particularly high when glucose dysregulation is present. Framingham Heart data found that the relative risk for diabetes was five-fold higher in patients with the syndrome.

In industrialized societies the prevalence of obesity and degenerative diseases such as diabetes, obesity, and cardiovascular diseases (CVD) is rapidly increasing especially in young individuals. For rapid urbanization and industrialization adult population are prone to fast food on the other hand parallely decreasing physical movement. Racial variation also enhances to develop the metabolic syndrome in adults because it is also established that Asian have higher fat mass than European even with similar BMI.

Neck circumference (NC) contributes to metabolic syndrome (MetS) likelihood beyond waist circumference and the MetS components ${ }^{9}$. BMI does not accurately define central body fatness," whereas neck circumference is an inexpensive way to determine the body's fat composition. The correlation between regional adiposity and a high neck circumference is strong. It has been shown that men with $\mathrm{NC}<37 \mathrm{~cm}$ and women with $\mathrm{NC}<34 \mathrm{~cm}$ probably have a low body mass index (BMI). Patients above these levels require a more comprehensive evaluation of their overweight and obesity status ${ }^{10}$.

A high correlation between NC and cardiovascular risk factors has been reported in obese patients ${ }^{11}$. The neck and thigh circumferences were used as indices of upperand lower-body subcutaneous tissue distribution, respectively, in a three-compartment body composition model. This model of interpretable anthropometry 
consisted of the visceral and subcutaneous adipose tissue masses as well as the lean body mass. Even after adjusting for these body compartments, NC, an index of upper-body subcutaneous adipose tissue distribution, was positively related to most cardiovascular risk factors. At the same time, thigh circumference was negatively related to the risk factors ${ }^{11}$.

Aging is known to be associated with increasing insulin resistance and declining glucose tolerance. G.Boden found that insulin sensitivity in men until around 60-70 yr of age appears to be determined more by body fat than by age. ${ }^{12}$

According to World Health Organization (WHO) non communicable diseases (NCDs) are important cause of disease burden, morbidity and mortality. At least 25\% of the deaths in primary and secondary government health facilities are caused by this diseases. ${ }^{13}$ The present study has been taken to explore the risk factors associated with newly diagnosed prediabetic and type 2 diabetic subjects.

\section{Subjects and Methods}

In this cross-sectional study one hundred forty-four subjects were randomly selected from the Diet and Nutrition Department, OPD (Out Patient Department), BIRDEM hospital where 44 impaired glucose tolerance (IGT) and 100 type2 diabetes mellitus (DM) subjects. This study was done during the period of September 2007 - September 2008. Social status was collected using a pre-designed questionnaire. Metabolic syndromes are considered by definition of National Cholesterol Education Program (NCEP) Adult Treatment Panel III (ATP III). Anthropometric indices [height (cm), weight (kg), Mid Upper Arm Circumference (MUAC) (mm), waist circumference (cm), hip-circumference $(\mathrm{cm})$ and neck-circumference (cm)] were measured using standard techniques with modern equipments. Body mass index (BMI) of the subjects was calculated using standard formula. BMI = Weight (kg)/[Height (m) $]^{2}$. Waist Hip Ratio (WHR) measured by waist(cm)/hip(cm). Serum glucose was measured by using glucose-oxidase method, lipid profile by enzymatic-colorimetric methods. Results were expressed as mean \pm SD and median (range) as appropriate student ' $t$ ' test and regression analysis were done as a test of significance.

\section{Results:}

In this study 44 IGT and 100 type 2 diabetes were studied where age (IGT, $40 \pm 7$ and DM, 40 \pm 8 ); and BMI (IGT, 24 \pm 4 and DM 24 \pm 4 ) were matched. No significant difference $(\mathrm{p}>0.05)$ were found of Neck- circumference

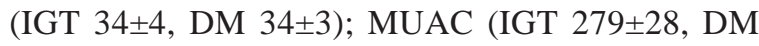

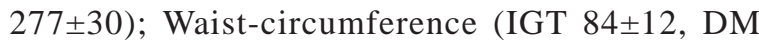
84 \pm 11 ); Hip-circumference (IGT 94 \pm 9 , DM 95 \pm 15 ) and WHR (IGT 0.91 \pm 076 , DM 0.89 \pm 0.01 ) among the study subjects. Median (range) Serum-TG cholesterol, HDL cholesterol, LDL cholesterol and Serum Cholesterol among the study subjects were not different between two groups.

No significant difference ( $\mathrm{p}>0.05$ ) was found between male

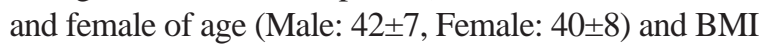
(Male: $24 \pm 4$, Female: $24 \pm 4$ ) in this study subjects. $\mathrm{M} \pm \mathrm{SD}$

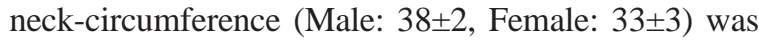
significantly higher $(\mathrm{p}<0.05)$ in males than females. MUAC, Waist- circumference, Hip- circumference and

\section{Table-I}

Anthropometric status $(M \pm S D)$ among the newly diagnosed pre diabetic and diabetic subjects

\begin{tabular}{|c|c|c|c|c|c|c|c|c|c|}
\hline Group & Age & BMI & MUAC & Neck- & Waist- & Hip_ & WHR & Systolic & Diastolic \\
\hline & (yrs) & $\left(\mathrm{kg} / \mathrm{m}^{2}\right)$ & $(\mathrm{mm})$ & $\begin{array}{c}\text { circum } \\
(\mathrm{cm})\end{array}$ & $\begin{array}{c}\text { circum } \\
(\mathrm{cm})\end{array}$ & $\begin{array}{c}\text { circum } \\
(\mathrm{cm})\end{array}$ & & $\mathrm{mmHg}$ & $\overline{(\mathrm{mmHg})}$ \\
\hline $\begin{array}{l}\mathrm{DM} \\
\mathrm{n}=100\end{array}$ & $40 \pm 8$ & $24 \pm 4$ & $277 \pm 30$ & $34 \pm 3$ & $84 \pm 11$ & $95 \pm 15$ & $0.89 \pm 0.01$ & $122 \pm 13$ & $79 \pm 10$ \\
\hline $\begin{array}{l}\text { IGT } \\
n=44\end{array}$ & $40 \pm 7$ & $24 \pm 4$ & $279 \pm 28$ & $34 \pm 4$ & $84 \pm 12$ & $94 \pm 9$ & $0.91 \pm .076$ & $120 \pm 13$ & $76 \pm 15$ \\
\hline $\begin{array}{l}\mathbf{t} / \mathbf{p} \\
\text { value }\end{array}$ & $-0.26 / 0.79$ & $0.15 / 0.88$ & $0.47 / 0.64$ & $-0.21 / 0.84$ & $-0.24 / 0.81$ & $0.44 / 0.66$ & $-1.17 / 0.24$ & $0.72 / 0.48$ & $1.44 / 1.15$ \\
\hline
\end{tabular}

Results were expressed as Mean \pm SD. Student $t$ test were analyzed as a test of significance. $\mathrm{p}<0.05$ were considered as level of significance. 


\section{Table-II}

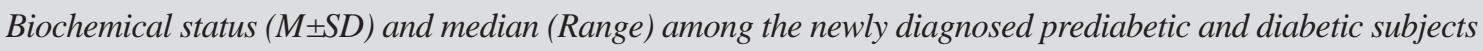

\begin{tabular}{lccccccc} 
Group & FPG & $\begin{array}{c}\text { ABF } \\
(\mathrm{mmol} / \mathrm{dl})\end{array}$ & $\begin{array}{c}\text { S.TG } \\
(\mathrm{mmol} / \mathrm{dl})\end{array}$ & $\begin{array}{c}\text { HDLC } \\
(\mathrm{mg} / \mathrm{dl})\end{array}$ & $\begin{array}{c}\text { LDLC } \\
(\mathrm{mg} / \mathrm{dl})\end{array}$ & $\begin{array}{c}\text { S.Chol } \\
(\mathrm{mg} / \mathrm{dl})\end{array}$ & $\begin{array}{c}\text { S.Creatinin } \\
(\mathrm{mg} / \mathrm{dl})\end{array}$ \\
\hline $\mathrm{DM} \mathrm{n}=100$ & $12 \pm 5$ & $18 \pm 6$ & $140(57-670)$ & $30(17-42)$ & $135(61-269)$ & $178(86-310)$ & $1.09 \pm 0.12$ \\
IGT n=44 & $6 \pm 0.84$ & $9 \pm 2$ & $160(68-764)$ & $30(18-54)$ & $146(77-216)$ & $193(117-239)$ & $1.11 \pm 0.14$ \\
t/p value & $6.78 / 0.00$ & $5.72 / 0.00$ & $1.37 / 0.20$ & $1708 / 0.86$ & $2758 / 0.243$ & $0.80 / 0.43$ & $-0.35 / 0.73$ \\
\hline
\end{tabular}

Results were expressed as Mean \pm SD. Student $t$ test were analyzed as a test of significance. $\mathrm{p}<0.05$ were considered as level of significance.

Table-III

\begin{tabular}{|c|c|c|}
\hline \multicolumn{3}{|c|}{ Distribution of BMI according to WHO cut point among the DM and IGT subjects } \\
\hline Group & $\begin{array}{c}\text { Group1 (BMI } \geq 30) \\
\text { No }(\%)\end{array}$ & $\begin{array}{c}\text { Group2 }(\mathrm{BMI} \leq 30) \\
\text { No }(\%)\end{array}$ \\
\hline $\mathrm{DMn}=100$ & $16(16)$ & $84(84)$ \\
\hline $\mathrm{IGTn}=44$ & $3(6)$ & 41(94) \\
\hline P-value & 0.09 & \\
\hline
\end{tabular}

$\chi^{2}$ was performed as a test of significance. $\mathrm{P}<0.05$ was considered as a test of significance

Table-IV

Distribution of Blood pressure among the DM and IGT subjects

\begin{tabular}{|c|c|c|c|c|c|c|}
\hline \multirow[t]{2}{*}{ Group } & \multicolumn{2}{|c|}{ ATP criteria } & \multicolumn{2}{|c|}{ EGIR criteria } & \multicolumn{2}{|c|}{ WHO criteria } \\
\hline & Group1 & Group 2 & Group 1 & Group 2 & Yes & No \\
\hline & $(\geq 130 / 85)$ & $(<130 / 85)$ & $(\geq 140 / 90)$ & $(<140 / 90)$ & $(\geq 140 / 90)$ & $<140 / 90$ \\
\hline & No (\%) & No (\%) & No (\%) & No (\%) & No (\%) & No (\%) \\
\hline $\mathrm{DMn}=100$ & 18(18) & $82(82)$ & $5(5)$ & $95(95)$ & $5(5)$ & $95(95)$ \\
\hline $\mathrm{IGTn}=44$ & $5(12)$ & $39(88)$ & $00(00)$ & $44(100)$ & $00(00)$ & $44(100)$ \\
\hline
\end{tabular}

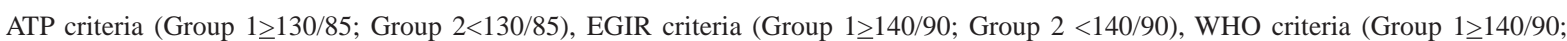
Group $2<140 / 90$ )

Table-V

Distribution of waist circumference among the DM and IGT subjects

\begin{tabular}{|c|c|c|c|c|}
\hline \multirow[t]{2}{*}{ Group } & \multicolumn{2}{|c|}{ ATP criteria } & \multicolumn{2}{|c|}{ EGIR criteria } \\
\hline & $\begin{array}{c}\text { Group1 } \\
\text { (Male } \geq 102 \mathrm{~cm} ; \\
\text { Female } \geq 88 \mathrm{~cm} \text { ) } \\
\text { No }(\%) \\
\end{array}$ & $\begin{array}{c}\text { Group } 2 \\
\text { (Male }<102 \mathrm{~cm} ; \\
\text { Female }<88 \mathrm{~cm}) \\
\text { No }(\%) \\
\end{array}$ & $\begin{array}{c}\text { Group } 1 \\
\text { (Male } \geq 94 \mathrm{~cm} ; \\
\text { Female } \geq 80 \mathrm{~cm}) \\
\text { No }(\%)\end{array}$ & $\begin{array}{c}\text { Group } 2 \\
\text { (Male }<94 \mathrm{~cm} ; \\
\text { Female }<80 \mathrm{~cm}) \\
\text { No }(\%)\end{array}$ \\
\hline $\mathrm{DMn}=100$ & $75(75)$ & $25(25)$ & $50(50)$ & $50(50)$ \\
\hline $\mathrm{IGTn}=44$ & $34(78)$ & $10(22)$ & $22(50)$ & $22(50)$ \\
\hline
\end{tabular}

WHR among the study subjects were not different between male and females. In this study metabolic syndrome were present using the definition of ATPIII, WHO and EGIR 4.9\%, $6.3 \%$ and $39.6 \%$ respectively (fig 1 ). According to ATP III,
$10.8 \%$ of the IGT and $20.9 \%$ of the DM subjects were hypertensive. Neck circumference was positively correlated with fasting blood glucose ( $r=0.19, \mathrm{p}=0.02)$ (fig. 1 ). Neck circumference was positively correlated with waist hip ratio (r=0.25, $\mathrm{p}=0.003$ ) (fig. 3) and $\mathrm{BMI}(\mathrm{r}=0.4, \mathrm{p}=0.02$ ) (fig. 4). 


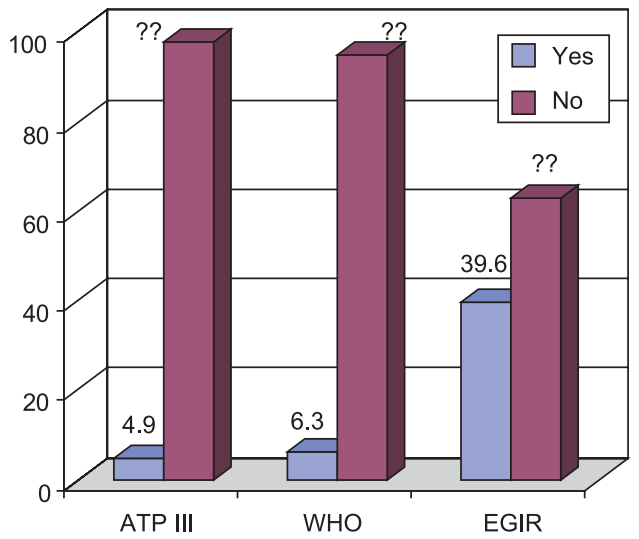

Fig.-1: Metabolic syndrome (\%) in the study subjects according to different definition

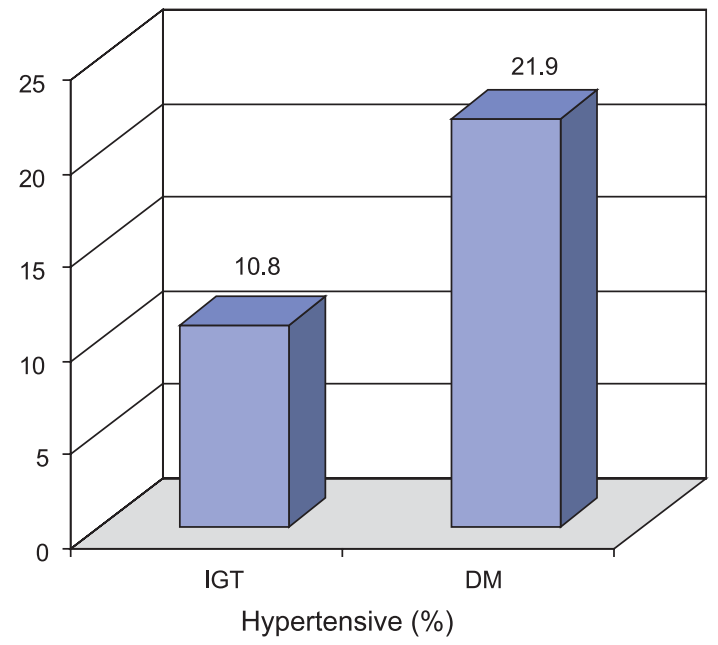

Fig 2: Hypertensive (\%) among the study subjects

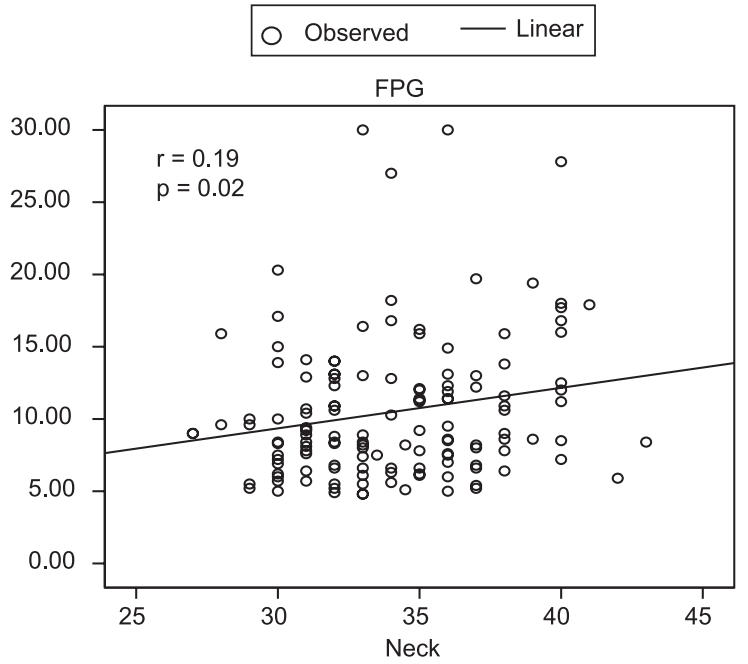

Fig.-3: Relationship between Neck circumference and fasting blood sugar among the study subjects

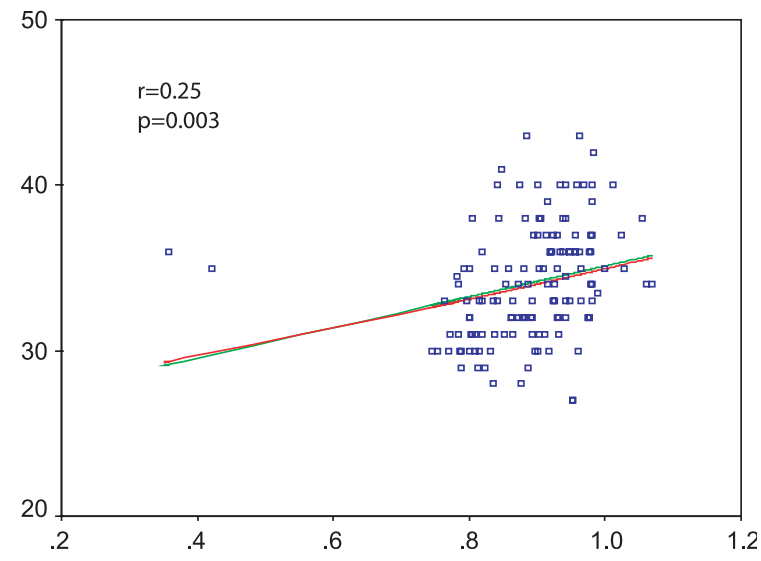

Fig.-4: Relationship between waist hip ratio and neck circumference among the study subjects

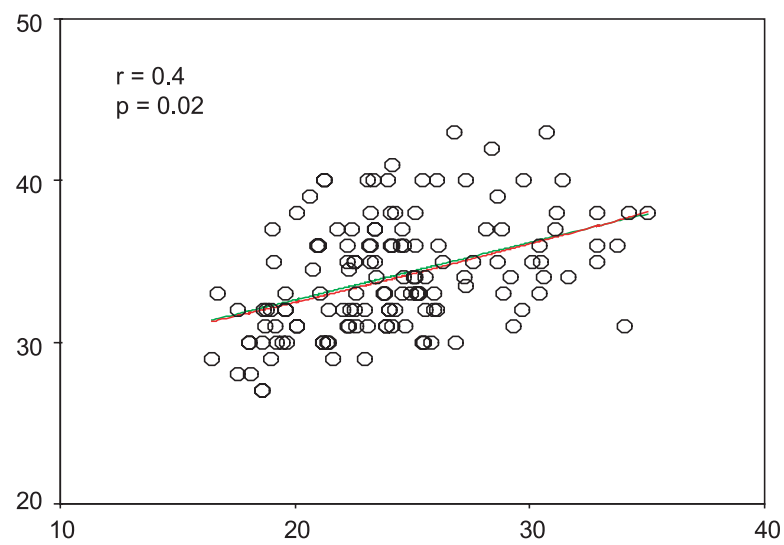

Fig.-5: Relationship between BMI and neck circumference among the study IGT and diabetic subjects

\section{Discussion}

Metabolic syndrome is characterized by a group of metabolic risk factors that include abdominal obesity, atherogenic dyslipidemia, elevated blood pressure and glucose intolerance or insulin resistance. The present study has been undertaken to assess the metabolic syndrome among the newly diagnosed diabetic and IGT subjects. In this study we have found that the risk age for both the prediabetic and diabetic subjects are 40 years of age. Similar result was found in a previous study conducted among Qatari males and females within aged 25-50 Years. ${ }^{14}$

Both prediabetic and diabetic subjects have BMI 24. Although WHO suggested normal BMI between 18.5 and 25 but recent studies suggest that BMI 23 should be the upper cut point for Asian because Asian peoples 
have higher fat mass than Europeans. Neck circumference (NC), as an upper body obesity index, is a simple screening measure for identifying overweight and obese patients. Although obesity results in metabolic abnormalities, upper-body obesity is more strongly associated with glucose intolerance, hyperinsulinemia, diabetes, hypertriglyceridemia, gout and uric and calculous disease than lower-body obesity ${ }^{9 ; 15}$; In our previous study, neck circumference ${ }^{9}$ as an index of upperbody obesity was found to be a simple and time-saving screening measure that can be used to identify overweight and obese individuals ${ }^{10}$. It has been shown that men with $\mathrm{NC}<37 \mathrm{~cm}$ and women with $\mathrm{NC}<34 \mathrm{~cm}$ probably have a low body mass index (BMI). In this study we have found that male have $<37 \mathrm{~cm}$ and female have $33 \mathrm{~cm}$. A high correlation between NC with glycemic status, BMI and waist circumference has been reported in obese patients 11. Waist hip ratio also determines the central obesity. In this study we have found that both prediabetic and diabetic subjects have higher waist hip ratio than normal range which is support with previous study. Prevalence of Metabolic syndrome in India was 8\% for men and 18\% for women whose average age is grater than 20years of age whereas highest prevalence were found in USA which is near $45 \%$ and $55 \%$ according to male and female with age range 45 to 49 years age using ATP criteria. The present study showed about 39.6\% MS were present in this study using EGIR criteria.

\section{Conclusion:}

From the above result it may concluded that

Forty years of age seems to be the alarming time for the development of prediabetic (IGT) and diabetes mellitus. Only glycemic status seems to be changed between the newly diagnosed prediabetic and diabetic subjects. Glycemic status affects at the BMI 24 and neck circumference $33 \mathrm{~cm}$. In this study $39.6 \%$ metabolic syndrome have present and $21.9 \%$ hyertensive may have in DM subjects. Waist hip ratio seems to be higher both in prediabetic and diabetic subjects. Neck circumference seems to be positively associated with glycemic status, waist hip ratio and BMI. About 39.6 \% MS seems to have present following EGIR but poor percentage MS have found following ATP III and WHO criteria.

\section{Referance}

1. Duvnjak L. Bulum T, Metelko • (2008). Hypertension and the metabolic syndrome Diabetologia. Croatica 37-44.
2. Fujita T(2010). Mineralocorticoid Receptors, Salt-Sensitive Hypertension, and Metabolic Syndrome. Hypertension. 55:813-818

3. Ervin RB (2009). Prevalence of Metabolic Syndrome Among adults 20 years of age and Over, by Sex, Age, Race and Ethnicity, and Body Mass Index: United States. National Health statistics report; 13:1-8

4. Alberti KG, Zimmet PZ (1998). Diabet Med 1998;15:539553.

5. National Cholesterol Education Program (NCEP) Adult Treatment Panel III final report 2002. Circulation; 106:31433421.

6. Expert Panel on Detection, Evaluation, and Treatment of High Blood Cholesterol in Adults: Executive Summary of the Third Report of the National Cholesterol Education Program (NCEP) (AT P III) 2001. JAMA 285 : 2486 -2497.

7. Mattsson N, Rönnemaa T, Juonala M, Viikari JS, Raitakari OT (2007). The prevalence of the metabolic syndrome in young adults. The Cardiovascular Risk in Young Finns Study. J Intern Med. 261(2):159-69

8. Jack Wang, John C Thornton, Mary Russell, Santiago Burastero, Steven Heymsfield, and Richard N Pierson Jr (1994). Asians have lower body mass index (BMI) but higher percent body fat than do whites: comparisons of anthropometric measurements Am J Clin Nutr ;60:23-8.

9. Onat A, Herqenc G, Yukselb H, Canc G, Ayhane E, Kayaf Z, Dursunoglug D (2009). Neck circumference as a measure of central obesity: Associations with metabolic syndrome and obstructive sleep apnea syndrome beyond waist circumference. Clinical Nutrition; 28(1): 46-51.

10. G Boden, X Chen, RA DeSantis and Z Kendrick (1993). Effects of age and body fat on insulin resistance in healthy men. Diabetes Care: 6 (5); 728-733

11. Sarah RP, Michael JP, Ralph BD Agostino, Ramachandran SV, Daniel L, Caroline SF (2009). Neck Circumference and Development of Cardiovascular Disease Risk Factors in the Framingham Heart Study. Circulation; 120:S509

12. Boden G, Song W, Pashko L, and Kresge K (2008). In Vivo Effects of Insulin and Free Fatty Acids on Matrix. Diabetes, 57; 476-883.

13. S Kuninori et al (2005). Prevalence of the metabolic syndrome using modified ATP III definitions for workers in Japan, Korea and Mongolia. J occup Health; 47126-135.

14. Peiris AN, Struve MF, Mueller RA., Lee MB, Kissebah AH (1988). Glucose metabolism in obesity: influence of body fat distribution. J Clin Endocrinol Metab 67: 760-767.

15. Nicola A, Steven MH, Abhimanyu G, Ronald MP and Scott MG (2002). Sex Steroid Hormones, Upper Body Obesity, and Insulin Resistance. The Journal of Clinical Endocrinology \& Metabolism 87; 10 4522-4527 